NBER WORKING PAPER SERIES

EXTENDING LIFE CYCLE MODELS OF OPTIMAL PORTFOLIO CHOICE:

SRATING FLEXIBLE WORK, ENDOGENOUS RETIREMENT, AND INVESTMENT DECISIONS WITH LIFETIME PAY

Jingjing Chai

Wolfram Horneff

Raimond Maurer

Olivia S. Mitchell

Working Paper 15079

http://www.nber.org/papers/w15079

\author{
NATIONAL BUREAU OF ECONOMIC RESEARCH \\ 1050 Massachusetts Avenue \\ Cambridge, MA 02138 \\ June 2009
}

This research reported herein was performed pursuant to a grant from the US Social Security Administration (SSA) to the Michigan Retirement Research Center (MRRC) as part of the Retirement Research Consortium. Additional research support was provided by Deutscher Verein für Versicherungswissenschaft, German Investment and Asset Management Association (BVI), and the Pension Research Council at The Wharton School of the University of Pennsylvania. Opinions and errors are solely those of the authors and not of the institutions with whom the authors are affiliated, nor of the National Bureau of Economic Research.

NBER working papers are circulated for discussion and comment purposes. They have not been peerreviewed or been subject to the review by the NBER Board of Directors that accompanies official NBER publications.

(C) 2009 by Jingjing Chai, Wolfram Horneff, Raimond Maurer, and Olivia S. Mitchell. All rights reserved. Short sections of text, not to exceed two paragraphs, may be quoted without explicit permission provided that full credit, including $\odot$ notice, is given to the source. 
Extending Life Cycle Models of Optimal Portfolio Choice: Integrating Flexible Work, Endogenous Retirement, and Investment Decisions with Lifetime Payouts

Jingjing Chai, Wolfram Horneff, Raimond Maurer, and Olivia S. Mitchell

NBER Working Paper No. 15079

June 2009

JEL No. D01,D03,D11,D14,G11,G22,G23,H31,H55,J14,J26

\begin{abstract}
$\underline{\text { ABSTRACT }}$
This paper derives optimal life cycle portfolio asset allocations as well as annuity purchases trajectories for a consumer who can select her hours of work and also her retirement age. Using a realistically-calibrated model with stochastic mortality and uncertain labor income, we extend the investment universe to include not only stocks and bonds, but also survival-contingent payout annuities. We show that making labor supply endogenous raises older peoples' equity share; substantially increases work effort by the young; and markedly enhances lifetime welfare. Also, introducing annuities leads to earlier retirement and higher participation by the elderly in financial markets. Finally, if we allow for an age-dependent leisure preference parameter, this fits well with observed evidence in that it generates lower work hours and smaller equity holdings at older ages as well as sensible retirement age patterns.
\end{abstract}

Jingjing Chai

Finance Department, Goethe University

Grüneburgplatz 1 (Uni-PF. H 23)

Frankfurt am Main

Germany

chai@finance.uni-frankfurt.de

Wolfram Horneff

Finance Department, Goethe University

Grüneburgplatz 1 (Uni-PF. H 23)

Frankfurt am Main

Germany

horneff@ finance.uni-frankfurt.de
Raimond Maurer

Finance Department, Goethe University

Grüneburgplatz 1 (Uni-PF. H 23)

Frankfurt am Main, Germany

rmaurer@wiwi.uni-frankfurt.de

Olivia S. Mitchell

Dept of Insurance \& Risk Management

University of Pennsylvania, Wharton School

3620 Locust Walk, St 3000 SH-DH

Philadelphia, PA 19104-6302

and NBER

mitchelo@wharton.upenn.edu 


\section{Extending Life Cycle Models of Optimal Portfolio Choice: Integrating Flexible Work, Endogenous Retirement, and Investment Decisions with Lifetime Payouts}

Previous research on portfolio choice and retirement patterns has evolved from three sources. First, the finance literature has investigated how investors save and allocate their portfolios across available capital market assets, typically safe bonds and risky stocks. ${ }^{1}$ Yet most of these studies are silent on the links between labor supply and investment behavior. Second, a large Social Security literature has explored how older people alter their work patterns in response to system retirement incentives, but that research devotes little attention to saving and portfolio allocation patterns. And third, the longevity risk literature has examined how annuity payout products can help protect against outliving one's income, but it has not yet explored how flexible labor supply might shape portfolio allocation and location decisions.

The present paper seeks to unify these three strands in a model which integrates the decisionmaking process of a consumer seeking to optimally select her saving, consumption, work hours, retirement age, and investment patterns in a life cycle context, where she has access to both the capital market (stocks and bonds) and annuities. We contribute to the finance and pension literature by making the work/retirement decisions endogenous, as the consumer can adjust both her retirement date and her employment hours during her worklife. We also add value to the Social Security literature by making investment and annuitization decisions endogenous to the lifecycle work and retirement choice. From an individual's assetliability perspective, we show how stochastic equity returns, uninsurable labor income shocks, and uncertain lifetimes help shape investment portfolio patterns.

This is not the first analysis that makes labor supply endogenous over the life cycle in an investment context, ${ }^{2}$ but we extend prior research by integrating flexible work hours and retirement ages with uncertain mortality and uninsurable labor income paths to show how they influence consumption, saving, and portfolio choice paths. Using our realistically calibrated life cycle model, we derive optimal work and retirement behavior as well as consumption and investment patterns over stocks, bonds, and payout annuities. Prior finance studies have assumed fixed retirement ages and predict that older people hold unrealistically high levels of equity; by contrast, we show that making labor supply endogenous and allowing purchase of payout annuities reduces older persons' equity share and substantially

\footnotetext{
${ }^{1}$ See for instance Campbell, Chan, and Viceira (2003) and Chacko and Viceira (2006).

${ }^{2}$ See for instance Gomes, Kotlikoff, and Viceira (2008), Polkovnichenko (2007), Chan and Viceira (2000) and Bodie, Merton and Samuelson (1992).
} 
increases work effort of the young - compatible with real-world evidence. We then illustrate how introducing annuities generates even more realistic models which permit earlier retirement and higher financial market participation by the elderly. Incorporating an agedependent leisure preference parameter is particularly interesting, as it generates a gradual decline in work hours and equity holdings with age, and a sensible dispersion in retirement ages which peak at age 62 ; these results are also consistent with empirical findings. ${ }^{3}$

Our work thus contributes to the portfolio choice, Social Security, and longevity risk management literatures. Many older finance research assumed that investors construct their portfolios independent of labor market influences, though a few authors do allow uninsurable labor income risk to shape household optimal consumption and investment decisions (Heaton and Lucas 1997; Viceira 2001; Cocco, Gomes, and Maenhout 2005) and they show how the optimal portfolio equity share falls with age due to the bond-like path of labor market earnings. Nevertheless, those authors maintain the exogeneity of labor supply. A few studies ${ }^{4}$ have embedded flexible work hours into a continuous time portfolio choice model, but they assume, unrealistically, that the worker can fully insure labor income risk in the capital market (i.e. that wages are perfectly correlated with a set of traded risky securities). A recent paper by Gomes, Kotlikoff, and Viceira (2008) analyzes endogenous work hours over the life cycle in a realistically calibrated portfolio choice discrete time model, but it requires the worker to mandatorily retire at a pre-specified age. Prohibiting consumers from controlling their retirement age is problematic, since working longer represents a key way in which older workers can react to unlucky shocks in both labor and capital markets (Mitchell and Fields 1984). In addition, deciding when to retire and claim one's Social Security benefits is one of the most important yet irreversible financial decisions that people make. Particularly in this current bear market, households may be able to hedge adverse capital market developments by increasing their work effort and by working longer.

A large literature in the public finance arena explores how consumption, saving, and work patterns respond to Social Security benefit incentives, but those studies do not devote much attention to portfolio investment behavior. Instead, that research takes seriously the way in which Social Security benefits depend on and/or influence retirement behavior. For instance, Laitner (2003) analyzes the effects of Social Security taxes and benefits on retirement ages, and Gustman and Steinmeier (2005) offer an important empirical analysis of

\footnotetext{
${ }^{3}$ See Gustman and Steinmeier (2005).

${ }^{4}$ C.f. Bodie, Merton, and Samuelson (1992); Bodie, Detemple, Otruba, and Walter (2004); Dybvig and Liu (2004); and Fahri and Panageas (2007).
} 
retirement patterns. ${ }^{5}$ Low (2005) and French (2005) investigate optimal consumption, saving, and labor supply patterns with stochastic and unspanned wages, but they abstract from the portfolio allocation problem.

A last literature on which we build analyzes the impact of longevity risk on life cycle portfolio management. These analyses demonstrate how investors chose between stocks, bonds, and survival-contingent payout streams or payout annuities, so as to optimize their saving and consumption patterns during retirement. ${ }^{6}$ Two studies integrate annuities into a realistically calibrated portfolio choice model (uninsurable labor income, uncertain life time, stochastic capital markets, borrowing constraints) over the full life cycle, but they do not endogenize the work hours or the retirement decision (Horneff, Maurer, Mitchell, and Stamos 2008; Horneff, Maurer, and Stamos 2008). Those authors demonstrate that annuities are valuable in that they offer investors the opportunity to give up liquidity in exchange for a survival-contingent premium known as the 'survival credit.' What remains to be done is to develop a realistically calibrated model with uninsurable labor income, uncertain asset returns, stochastic mortality, flexible hours, choice of retirement date, and variable as well as fixed annuities in the portfolio choice set. To this task we turn next.

\section{The Consumer's Life Cycle Problem}

\subsection{Preferences}

We employ a discrete time model $t \in\{0, \ldots, T+1\}$, where $t$ refers to the individual's adult age (computed as actual age minus 19 assuming the relevant lifespan starts at age 20). The individual has an uncertain lifespan and may live for a maximum of $T$ years (indexed from 1 to $T$ ). The parameter $p_{t}^{s}$ denotes the (subjective) probability of surviving to period $t+$ 1 , given the consumer is alive at $t$. In the last period, $p_{T+1}^{s}$ is equal to zero. Individual preferences are characterized by a CRRA utility function $u\left(C_{t}, L_{t}\right)=\frac{1}{1-\rho}\left(C_{t}^{1-\alpha} L_{t}^{\alpha}\right)^{1-\rho}$ defined over a consumption good and leisure, where the substitution between leisure and consumption takes the Cobb-Douglas form. ${ }^{7}$

The recursive definition of the value function is given by:

\footnotetext{
${ }^{5}$ Other studies focus on the empirical analysis of retirement patterns; see Buchinsky, Rust, and Benitez-Silva (2000) and Benítez-Silva and Heiland (2008).

${ }^{6}$ See Horneff, Maurer, Mitchell, and Stamos (2009), Milevsky, Moore, and Young (2006), and Milevsky and Young (2007); a broad literature review appears in Horneff, Maurer, Mitchell, and Dus (2008).

${ }^{7}$ Low (2005) uses this same formulation but his analysis of work patterns prior to retirement is silent on portfolio choices. In sensitivity analysis below, we also evaluate the trade-off between leisure and consumption using a modified Cobb-Douglas preference function as in Gomes, Kotlikoff, and Viceira (2008).
} 


$$
V_{t}=\frac{\left(C_{t}^{1-\alpha} L_{t}^{\alpha}\right)^{1-\rho}}{1-\rho}+\beta E_{t}\left(p_{t}^{s} V_{t+1}\right)
$$

with terminal utility $V_{T}=\frac{\left(C_{T}^{1-\alpha} L_{T}^{\alpha}\right)^{1-\rho}}{1-\rho}$. The parameter $\rho$ is the coefficient of relative risk aversion, and $\beta<1$ is the time preference. Here $C_{t}$ denotes the level of consumption and $L_{t}$ is leisure at time $t$. Leisure is measured as a percent of available time and lies in the interval $L_{\min } \leq L_{t} \leq 1$. The individual's work hours are measured as a fraction of the total available time, i.e. $1-L_{t}$, whereas after retirement, labor supply is equal to zero. In what follows, the minimum leisure time is set $L_{\min }=1 / 3$; in other words, the maximal labor supply is $2 / 3$ of available time. Leisure preferences are governed by the parameter $\alpha$, where (for $\rho>1$ ) a higher value of $\alpha$ corresponds to an increasing (decreasing) marginal utility of leisure (consumption). ${ }^{8}$ Below we work with a fixed value for $\alpha$, but in sensitivity analysis we also permit $\alpha$ to be age-dependent, so declining health at older ages may induce a lower valuation of leisure (c.f. Buchinsky, Rust, and Benitez-Silva 2000). We abstract from bequests. ${ }^{9}$

\subsection{Labor and Retirement Income}

Our model accounts for a flexible retirement age within the parameters generally adopted by the US Social Security system. That is, the worker can retire (consume full leisure) between the 'early' retirement age (ERA; set here to age 62) and the 'latest' retirement age ( $L R A$; set here to age 70$)$. The individual receives a real wage when working and decides what fraction of her time to devote to the job. This labor supply decision $\left(1-L_{t}\right)$ then influences gross labor earnings. Labor earnings is reduced by a given fraction of expenditures related to housing and other durables expenditures $h(t)$. Also individuals must pay taxes on their labor earnings (after housing expenditures) according to the proportional rate $t^{l}$. Thus after-tax disposable labor earnings during the work life $(\mathrm{t}<\tau, \tau \in[62,63, \ldots, 70])$ are given by:

$$
\begin{aligned}
& Y_{t}=(1-h(t))\left(1-t^{l}\right)\left(1-L_{t}\right) \exp (w(t)) E_{t} u_{t}, \\
& E_{t}=E_{t-1} n_{t},
\end{aligned}
$$

where $w(t)$ is a deterministic function of wage rates with respect to age allowing for the

\footnotetext{
${ }^{8}$ In the special case where $\alpha$ is zero, this is consistent with the conventional utility function used in many prior studies of life cycle portfolio allocation (c.f. Campbell and Viceira 2001; Cocco, Gomes, and Maenhout 2005; Viceira 2001; and Yao and Zhang 2005).

${ }^{9}$ Hurd (1989) estimates the strength for intentional bequest preference to be close to zero, and therefore concludes that for most households bequest is accidential.
} 
empirically observed hump-shaped earnings profile. $E_{t}$ is a permanent labor earnings component with innovation $n_{t}$, and $u_{t}$ reflects a transitory shock uncorrelated with $n_{t}$. The logarithms of both $n_{t}$ and $u_{t}$ are assumed to be normally distributed with mean zero and standard deviation of $\sigma_{N}$ and $\sigma_{U}$. The correlation between the permanent earnings and the stock market is denoted by $\phi_{n}$. In our discrete time model, $\tau$ is the endogenous retirement age which is treated as both a decision variable as well as a state variable, with nine possible values from age 62 to 70 .

After retirement, the household receives after-tax benefits payments from Social Security defined as follows: ${ }^{10}$

$Y_{t}=(1-h(t))\left(1-t^{r}\right)\left(\frac{\sum_{t=1}^{K}(1-\bar{L}) \exp (w(t))}{K}\right) \zeta E_{K} F_{\tau, N R A}$, where
$F_{\tau, N R A}=\exp \left(-g_{1}(N R A-\tau)\right) I_{(\tau \leq N R A)}+\exp \left(-g_{2}(N R A-\tau)\right) I_{(\tau>N R A)}$

and where $\zeta$ is the Social Security replacement rate based on lifetime average earnings. Here $1-\bar{L}$ stands for the average fraction of available time worked during the work life. The average lifetime earnings level is approximated by $\left(\frac{\sum_{t=1}^{K}(1-\bar{L}) \exp (w(t))}{K}\right)$ where $K$ denotes the period in which the individual attains her normal retirement age (NRA). Social Security benefits are taxed at a rate $t^{r}$ which may be lower than the wage tax rate to account for progressive taxation. $I$ is an indicator function which identifies whether the individual retires at or prior to the NRA, or later. $F_{\tau, N R A}$ is a factor which depends on the NRA and the endogenous retirement age $\tau$. If the worker retires prior to the $N R A, F_{\tau, N R A}$ works as an actuarial reduction factor permanently reducing benefit payments (here $g_{1}$ and $g_{2}$ are positive constant). If the consumer works after the $N R A$, the benefit is increased by the delayed retirement credit $F_{\tau, N R A} \cdot{ }^{11}$

\footnotetext{
${ }^{10}$ Our model assumes that people claim retirement benefits and move to full leisure at the same age; Coile, Diamond, Gruber, and Jousten (2002) show that this is actually what most people do.

${ }^{11} \mathrm{We}$ abstract from other institutional aspects of Social Security rules such as the earnings test for retirees who return to work after retirement.
} 


\subsection{Capital and Payout Annuity Market Parameters}

The individual may access capital markets by investing in two different asset classes: riskless bonds and risky stocks. The real bond gross return is constant over time and denoted by $R_{f}$. The real gross risky stock return at time $t$ is labeled $R_{t}$ and evolves according to a geometric random walk with drift. This implies that the log-returns for stocks $\ln \left(R_{t}\right)$ are serially independent and identically normally distributed with mean $\mu_{\mathrm{s}}$ and standard deviation $\sigma_{\mathrm{s}}$. The return on assets is taxed at rate $t^{c}$. We also include in the investment opportunity set variable payout life annuities where the payouts may reflect an underlying portfolio of equities or bonds (or both). These are insurance contracts between an annuitant and an insurer where the purchaser pays the insurer an initial premium $A_{t}$ and receives a pre-specified number of fund units $n_{t}$ for life, conditional on survival. This is computed according to:

$$
A_{t}=(1+\delta) Z_{t}^{a}(t) n_{t+1}(t) \sum_{s=t+1}^{T} \frac{p^{a}(t, s)}{(1+A I R)^{s-t-1}} .
$$

Here $\delta$ is an expense or loading factor charged by the insurance company to cover administrative costs, and the price of a fund unit at time $t$ is $Z_{t}^{a}$. Also $p^{a}(t, s)=\prod_{t}^{s-1} p_{t}^{a}$ is the cumulative conditional survival probability for an individual age $19+t$ to survive until age $19+s$, and $A I R$ is the assumed interest rate. The single-period survival probability $p_{t}^{a}$ is specified by a mortality table used by the insurance company and may differ from the individual's subjective survival probability $p_{t}^{s}$. This allows us to model asymmetric mortality beliefs and address the problem of adverse selection in the private annuity market. The survival-contingent income from the annuity is equal to $\hat{P}_{t}=n_{t} Z_{t}^{a}, \quad t \in(1, \ldots, T)$. The $A I R$ determines how the number of fund units is supposed to change over time, according to $n_{t}=n_{1}\left(\frac{1}{(1+A I R)}\right)^{t-1}$; it may be thought of as the pre-determined shrinkage rate for the number of fund units.

The process describing the value of the fund unit is as follows:

$$
Z_{t+1}=Z_{t} R_{t+1}^{a}
$$

where $R_{t+1}^{a}=R_{f}+\pi_{t}^{a}\left(R_{t+1}-R_{f}\right)$ is the growth rate of the asset underlying the fund, and where $\pi^{a}$ is the stock fraction chosen inside the variable annuity. The equation describing the evolution of payouts for a specific annuity may be written as: 


$$
\hat{P}_{t+1}=\frac{\hat{P}_{t} R_{t+1}^{a}}{1+A I R} .
$$

This equation highlights that the annuity payment rises when $R_{t+1}^{a}>1+A I R$; it falls when $R_{t+1}^{a}<1+A I R$; and it is constant when $R_{t+1}^{a}=A I R .^{12}$ The classical annuity with lifelong fixed payouts results is a special case, whereby the portfolio inside the annuity is fully invested in bonds (i.e. $\pi^{a}=0$ ) and the AIR is set equal to the riskless interest rate (i.e. $1+A I R=R_{f}$ ).

\subsection{Wealth Transition and Optimization}

Each period, the household decides how to allocate its cash on hand, $W_{t}$, to bonds $B_{t}$, stocks $S$, purchase of payout annuities $A_{t}$, and consumption $C_{t}$. The budget constraint becomes:

$$
W_{t}=S_{t}+B_{t}+A_{t}+C_{t} .
$$

With this investment and consumption strategy, next period's wealth $W_{t+1}$ is given by:

$$
W_{t+1}=\left(S_{t} R_{t+1}^{s}+B_{t} R_{f}\right)\left(1-t^{c}\right)+t^{c}\left(B_{t}+S_{t}\right)+P_{t+1}+Y_{t+1}
$$

where $P_{t+1}$ is the sum of annuity payments received from all previously-purchased annuities. Here $Y_{t+1}$, which below we call labor income, is defined in equations (2) and (3) as labor earnings prior to retirement, and Social Security benefits after retirement. The recursive evolution equation for the sum of after-tax payouts from all previous annuities purchased can be written as: ${ }^{13}$

$$
P_{t+1}=\left[\frac{P_{t}}{(1+A I R)}+A_{t}\left(\sum_{s=t+1}^{T} \frac{p^{a}(t, s)}{(1+A I R)^{s-t-1}}\right)^{-1}\right]\left(\left(R_{f}+\pi_{t}^{a}\left(R_{t+1}-R_{f}\right)-1\right)\left(1-t^{c}\right)+1\right),
$$

The individual's optimization problem is now to maximize the utility in (1) with respect to the appropriate asset allocation between liquid bonds and stocks, illiquid annuities, consumption, leisure, and the retirement decision:

$$
\max _{C_{t}, L_{t}, S_{t}, B_{t}, A_{t}, \tau \in[62,63, \ldots, 70]} V_{t}
$$

We rule out short-selling in stocks and bonds and preclude the household from borrowing against future labor, pension, and annuity income by imposing the non-negativity restrictions

\footnotetext{
${ }^{12}$ A more detailed discussion of how AIR influence payout profiles appears in Horneff, Maurer, Mitchell, and Stamos (2009).

${ }^{13}$ Here the annuities are held in a non-tax qualified account and interest earnings are taxed as capital gains at a rate below the tax rate on labor earnings but higher than the Social Security tax rate (i.e. $t^{r}<t^{c}<t^{l}$ ). This is an approximation to the exclusion ratio approach implemented by the US tax authority adopted for computational simplicity; for more detail on annuity taxation, see Brown, Mitchell, Poterba, and Warshawsky (1999) and Milevsky (2006).
} 
$A_{t}, \pi_{t}^{a},\left(1-\pi_{t}^{a}\right), S_{t}, B_{t} \geq 0$.

In our model, there are five state variables: cash on hand $W_{t}$, annuity payouts from previously purchased annuities $P_{t}$, the permanent labor earnings level $E_{t}$, retirement age $\tau$, and age t. To reduce the problem by one state variable we normalize the continuous state variables cash on hand and annuity payouts with the permanent labor earnings component. Next we discretize the (normalized) continuous state variables and solve the optimization problem by backward induction in a four-dimensional state space. For computations, we use a $40(W) \times 30(P) \times 42(t)$ grid space before and a $40(W) \times 30(P) \times 39(t) \times 9(\tau)$ after ERA. For each grid point we evaluate the policy and value functions using Gaussian quadrature integration and cubicsplines interpolation.

\subsection{Model Calibration}

The individual's lifespan is modeled from age 20 to $100(T=81)$. In our base case, preference parameters are set to standard values in the life cycle literature, namely a coefficient of relative risk aversion of $\rho=5$ and a discount factor $\beta=0.97$. The leisure preference value $\alpha$ is set equal to 0.59 in the base case, which is the mean of the agedependent profile used in Buchinsky, Rust, and Benitez-Silva (2000) and close to Laitner's (2003) value of 0.63 . The one-period survival rate $p_{t}^{s}$ is calculated by the US 1996 population 2000 table for female. Later, in the sensitivity analysis, we vary both the preference parameter for risk aversion and for leisure.

The analysis also sets the mean equity log-return at $\mu_{\mathrm{s}}=3.01 \%$ and the corresponding volatility parameter $\sigma_{\mathrm{s}}=19.34 \%$, equivalent to a yearly expected gross real return of 1.05 and standard deviation of $20.5 \%$; the assumed real riskless rate $R_{f}$ is 1.02 , in line with current expectations. The deterministic component of the wage rate process follows Fehr, Jokisch, and Kotlikoff (2006), reflective of middle-income households. The standard deviations $\sigma_{N}$ and $\sigma_{u}$ are equal to $10.95 \%$ and $13.89 \%$ (as reported in Cocco, Gomes, and Maenhout 2005, and used by Gomes, Kotlikoff, and Viceira 2008). The correlation between stock returns and permanent and transitory earnings shocks $\phi_{\mathrm{n}}$ is set to zero, consistent with empirical evidence in Cocco, Gomes, and Maenhout (2005). Returns on assets are assumed to be taxed at 20\%; labor earnings are taxed at 30\% following Gomes, Kotlikoff, and Viceira (2008). Housing-related expenditures are modeled as in Gomes and Michaelides (2005).

In the base case, the model assumes that the worker has a fixed labor supply of 8 hours per day and works 5 days a week (this is relaxed subsequently). This is motivated by Laitner 
(2003), who posits 112 waking hours per week, so a fixed 40-hour work week is equivalent to roughly one-third (0.36) time (i.e. $1-\mathrm{L}_{\mathrm{t}}=40 / 112$ ). The average labor supply $1-\bar{L}$ is also set equal to the same fraction. The Social Security benefit structure is similar to that in effect in the United States. The benefit replacement rate $\zeta$ is set to 0.55 as per Mitchell and Phillips (2006); the actuarial reduction rate for early retirement benefits is $g_{1}=0.0713$ and the delayed retirement crediting rate is $g_{2}=0.077$ as in Buchinsky, Rust, and Benitez-Silva (2000). Social Security benefits are taxed at a rate of $15 \%$ as in Gomes, Kotlikoff, and Viceira (2008). To price the annuities, the assumed interest rate is set to $2 \%$, the insurance loading factor $\delta$ is $2.38 \%$ (in line with industry leaders such as Vanguard), and we use conditional survival probabilities $p_{t}^{a}$ from the US 1996 female annuitant 2000 mortality table to account for potential adverse selection in the voluntary annuity market.

\section{Results}

In what follows, we present three variants of our model so as to compare key outcomes of interest including saving and investment patterns, annuitization purchases, work hours, and retirement ages. First, we develop a base case where the consumer can elect her retirement age endogenously but cannot adapt work hours per week and lacks access to annuities. Second, we allow work hours to be endogenous; and finally, we introduce annuities into the picture. To do so, we use the optimal feedback controls obtained from the stochastic optimization model and compute expectations using 10,000 Monte Carlo simulations. Sensitivity analysis with respect to key parameters is provided in Section 3.

\subsection{Fixed Hours, Flexible Retirement, No Annuity}

We analyze a moderately risk-averse worker $(\rho=5)$ whose chooses her appropriate consumption, investment, and labor supply strategy given a fixed workweek (i.e. 40-hour week work) but able to select a retirement age endogenously. Figure 1 traces expected consumption, labor income, and saving patterns by age, as well as the Cobb-Douglas function of leisure and consumption $F\left(C_{t}, L_{t}\right)=C_{t}^{1-\alpha} L_{t}^{\alpha}$ which enters the utility function. All values are normalized by the worker's first-year labor income. The results show that the household saves until age 47; liquid assets peak at age 55 in expectation when they amount to about eight times first-year labor income. Average labor income follows a hump-shaped pattern until age 65 and falls substantially when most households claim Social Security benefits at the endogenous retirement age. The consumption profile also drops sharply after age 65 and falls 
thereafter, since households are willing to trade off purchased goods for leisure time once this is feasible. Nevertheless, the Cobb-Douglas function F which combines consumption and leisure is quite smooth over the life cycle, as should be expected. Note that in expectation, the household would be anticipated to rationally exhaust its savings around the age of 80 , relying fully on Social Security benefits after that.

Figure 1 here

Figures 2 and 3 offer detailed insights into the household's expected asset allocation patterns by age and retirement choices. Panel A in Figure 2 indicates that, in this environment, people will hold a very high fraction of their saving in stocks over the life cycle, conditional on having certain minimal level of saving. Even at age 80 , the equity percent is still $97 \%$. These equity fractions are considerably higher than reported in prior studies that do not allow endogenous retirement (Cocco, Gomes, and Maenhout 2005; Gomes, Kotlikoff, and Viceira 2008). The reason is that, here, households will react to adverse stock market developments by delaying retirement and saving more. Thus the inherent hedging possibility of labor supply allows the household to take on more financial risk until the oldest possible retirement age, 70. Also in Panel B we show that the capital market participation rate of modeled households decreases sharply with age. Panel B in Figure 2 shows that about half of the modeled households (55\%) participate in the capital market at age 70 ; by age 80 , fewer than $10 \%$ do so. Such high levels of equity holdings and low participation rates are actually not realistic for the older population. For instance, the U.S. Social Security Administration (2009) reports that about $55 \%$ of the $80+$-population still receives income from assets which amounts to $10 \%$ of total income. Most of the asset income results from interest payments, and only one fifth receive any income from stocks. Therefore the model predicted market participation rates are low compared to observed behavior, and equity fractions, conditional on participation, seem high.

\section{Figure 2 here}

In Figure 3 we illustrate household work hours and retirement patterns. In this case, by assumption, the consumer works a 40-hour week work until retirement. As Panel A shows, labor supply patterns drop off as of the early retirement age of 62 , and by age 66 , all will have fully retired. Panel B displays the fraction of people electing to retire at each age: the model predicts that $14 \%$ will retire early, and the majority leaves at age 66 .

Figure 3 here 


\subsection{Flexible Hours, Flexible Retirement, No Annuity}

Next we allow the household to also choose its work intensity in the pre-retirement period, whereby the maximal labor supply is $2 / 3$ of available time; in our case this is equivalent to a maximum of 75 working hours per week (i.e. 112*2/3). Results appear in Figure 4, where we see that the household now saves much more than was true in Figure 1. Liquid assets now peak at earlier (at age 54 vs. 55 in Figure 1) and higher, amounting to over 10 times first-year labor income. On average, consumption is higher early in the work life and it falls after the normal retirement age; the function $\mathrm{F}$ is again smoothed over the life cycle.

Figure 4 here

Turning to equity market participation patterns, Figure 5 and Figure 2 are quite similar: people still hold a surprisingly high fraction of their saving in stocks conditional on participation in the capital market (5A) but few households actually hold stocks and bonds after retirement (5B). Comparing Figure 6 with Figure 3 reveals much more striking differences. The individual able to adjust her labor hours ends up working much more during her younger years, and then she gradually curtails labor effort after middle age. Essentially, she profits from working harder early in life, producing higher absolute saving and more capital market returns. Also, sharply different from the prior case, virtually all households work up to the normal retirement age; after that, households gradually reduce their working hours.

Overall, endogenizing both the retirement age and work hours permits the consumer to enjoy reduced hours at older ages, a pattern consistent with empirical evidence (Low 2005). Therefore this second model generates a relative realistic labor supply pattern, though predicted high equity holdings and low capital market participation patterns still appear inconsistent with observed behavior.

Figures 5 and 6 here

\subsection{Flexible Hours, Flexible Retirement, and Fixed/Variable Payout Annuities}

In a third scenario, we allow the household to not only select her work intensity and retirement age, but also to hold annuities as well as stocks and bonds. Figure 7 shows the expected life cycle profiles for the case where payout annuities are available; in Panel A the consumer may purchase fixed annuities, and in Panel B variable annuities. The results show that saving levels in liquid stocks and bonds are lower than in the environment without annuities shown in Figure 4. Now the consumer saves about 20\% less at the peak of lifetime saving since she has the opportunity to purchase annuities and receive the survival credit in 
later life. In the fixed annuity world, the worker will gradually purchase annuities between ages 48 and 75; the buying peaks at age 62 (when she spends about 13\% of first-year labor income). Yet annuity payouts are not large, and in old age, people again live mainly on Social Security benefits. By contrast, in the variable annuity world, consumers buy substantial amounts of variable annuities from age 40 to 67, and the purchasing peaks at age 47 (now, at $190 \%$ of first-year labor income). Variable annuities then generate important levels of retirement income flows above and beyond Social Security benefits.

Figure 7 here

Figure 8 depicts the household's expected trajectory for the fraction held in liquid stocks and bonds, and in the fixed annuity, subject to having certain minimal levels of financial and annuity wealth. Panel 1A reports the expected trajectory for the fraction held in liquid stocks, bonds, and the fixed annuity; while Panel 2A plots the expected trajectory for the fraction held in stocks and bonds, inside and outside the variable annuity. As before, liquid stocks are the most important investment vehicle early in life, but in midlife, the individual switches gradually out of equities into fixed annuities (1A) beginning around the early retirement age. By around age 80 , the entire portfolio has been moved into fixed annuity holdings to take advantage of the survival credit. When the consumer can buy variable annuities, the same general pattern (2B) obtains but it begins much younger, at around age 45 . The reason is that the illiquidity inherent in the variable annuity can be offset by flexibility in both working hours and the retirement age. Earlier purchases provide access to the survival credit and expected equity returns earlier in life.

Panels $1 \mathrm{~B}$ and $2 \mathrm{~B}$ of Figure 8 show the fraction of households not participating in the capital or annuity markets by age. While participation patterns by the young are virtually the same as before, there is a striking difference among the older population. Now most do not rely only on Social Security benefits; rather, they also receive income from purchased annuities. This is very clear in the case of variable annuities (2B), where virtually all retirees optimally annuitize a portion of their wealth.

\section{Figure 8 here}

Figure 9 traces out the pattern of work hours when annuities are available. Here we see that work hours are similar irrespective of the type of annuity provided, and similar to those without the annuity. Further, as before, people gradually reduce their working hours over time. But there are substantial differences in retirement patterns, as is clear from the retirement rate table. Without annuities, $11 \%$ of the workers retire at the age of 66 and some still work until age 70 (6B). With fixed annuities, retirement begins as early as age 62 and 
$18 \%$ have left by age 66 ; all have left the workforce by 68 . Finally, with variable annuities, the distribution is shifted even earlier, with $60 \%$ having retired by age 66 and all having left by age 67 . In the US context, fixed payout annuities have been the product most widely sold in the past, with variable payout annuities growing in popularity only recently. Yet the evident appeal of the variable payout product suggests that these are likely to become more popular as the population ages.

\section{Figure 9 here}

Overall, then, people retire earlier because they can secure a "second income" from their annuity purchases to supplement their Social Security benefits. In this case, endogenizing both work hours and retirement, and including annuities, the model generates hump-shaped work hour patterns, elderly equity holdings similar to those observed in the real world, and capital market participation patterns also consistent with empirical evidence.

\subsection{Welfare Analysis}

Next we examine the impact on consumer welfare of adding labor supply flexibility and annuities to the opportunity set. ${ }^{14}$ To do so, we show in Table 1 the changes in consumer wellbeing in two ways: standard consumption-equivalent variations or relative utility gains (Column a), and also gains relative to what consumer would be willing to give up as a percent of her first-year labor earnings (Column b). Welfare gains are computed with reference to the lifetime utility level of a consumer with fixed work hours and retirement age and who lacks access to annuity markets appear in Row (0). ${ }^{15}$ Row (1) depicts the case of a worker who has fixed work hours but a flexible retirement age; this additional degree of freedom with respect to leisure provides a rather substantial lifetime utility gain of $4.4 \%$. This can also be measured as a $50 \%$ gain in his first-year labor income, versus the reference case. In Row (2), the worker can adapt both her work hours and her retirement age; relative to the reference case, utility gains are even larger, at $6.6 \%$ of lifetime utility, equivalent to a $61 \%$ increase in her first-year labor income. Rows (3 and 4) permit both flexible hours and retirement ages; in the former case, only fixed annuities are available, and in the latter case, variable annuities are also available. Here we see that utility gains rise further in a world with annuities compared to Rows (1 and 2) where the annuity market is shut down; in the most flexible case, Row (4), lifetime utility rises by $7 \%$.

\section{Table 1 here}

\footnotetext{
${ }^{14}$ Computational details appear in the Technical Appendix.

15 The consumption-equivalent variable in utility terms is a standard metric; we also present the worker's first year of labor income as a metric for the welfare change as in Gomes, Kotlikoff, and Viceira (2008).
} 
In sum, the marginal benefit from having access to annuities is positive and important in the life cycle context, as is labor market flexibility in the form of adjustable weekly hours of work and retirement age. We note that these increases in lifetime utility are computed from the vantage point of a 20-year old where labor market flexibility is a driver for boosting forward-looking lifetime utility. Prior research has demonstrated that, for an individual on the verge of retirement, access to annuities is similarly valuable (Mitchell, Poterba, Warshawsky, and Brown 1999; Horneff, Maurer, Mitchell, and Stamos 2009).

\section{Sensitivity Analyses}

To assess how robust our results might be to alternative formulations of household preferences, we next explore several alternative formulations of key utility parameters, namely risk aversion and the value attached to leisure. Of particular interest are the effects on labor supply, work hours, and retirement ages, summarized in Figure 10 and Table 2. In addition, we evaluate the effects on asset allocation patterns and the likelihood of participating in the capital and annuity markets, reviewed in Tables 3 and 4. In all instances, the benchmark (Case 1) is designed so the worker may elect flexible work hours and retirement age, and she also has access to stocks, bonds, and fixed payout annuities. Variants include Case (2) which boosts leisure preferences (to $\alpha=0.8$ ); Case (3) reduces the consumer's risk aversion (to $\rho=3$ ); and Case (4) where risk aversion is increased (to $\rho=10$ ). In Case (5) we use a modified Cobb Douglas (MDC) utility function which alters the relative weights on consumption and leisure. Specifically, the argument of the utility function is specialized to $F_{t}\left(C_{t}, L_{t}\right)=C_{t} L_{t}^{\alpha}$ where $\alpha$ is set to 0.9 as in Gomes, Kotlikoff, and Viciera (2008). In Case (6) we make $\alpha$ agedependent to allow the utility of leisure to deteriorate with poorer health at older ages (as in Rust et al. 2000). The leisure parameter $\alpha(t)$ is given by $\alpha=1-0.6 /(1+t / 50)$ where $t$ is the period. In addition we set the coefficient of relative risk aversion to $\rho=3$, a value in line with the economics literature. ${ }^{16}$

Figure 10, Tables 2-3-4 here

Not surprisingly, labor supply patterns over the life cycle depend importantly on the way in which the utility function is formulated in Figure 10. In the benchmark case of Figure 10, the average worker starts out working over 40 hours per week and in her mid-30's she peaks at just under 50 hours per week; thereafter work hours fall gradually until retirement in her late 60’s. Everyone has retired after age 68 (Table 2). By contrast, the leisure-lover (Case

\footnotetext{
${ }^{16}$ See Feldstein and Ranguelova (2001) who argue that the typical $\rho$-values used in the finance literature seem implausibly high.
} 
2) works only about half-time over her entire worklife and leaves employment as early as possible; all such persons are fully retired by age 63. Work hours in Case 3 and 4 are quite similar to those in the benchmark case, indicating that varying risk aversion does not much influence hours. Yet there are substantially different retirement age outcomes: the most risk averse consumer is also likely to work until forced out at age 70, whereas risk lovers have a more dispersed retirement age distribution (Table 2). The pattern for Case 5 results in an unrealistically high level of work effort over the life cycle, in that young and middle-aged employees are predicted to work over 60 hours per week and must be forced to retire at age 70. Finally, Case 6 with the age-dependent utility of leisure parameter results in young persons are taking on extremely high labor hour commitments, but their effort drops off as health problems set in. Additionally they are likely to retire early, with the witdrawal pattern peaking at age 62 .

The portfolio implications of this robustness analysis are summarized in Tables 3 and 4. For instance, the leisure lovers (those who worked relatively little during their youth) also tend to invest heavily in equity until late in life (Tables 3 and 4, Case 2). Those with lower levels of risk aversion are, not surprisingly, much more likely to invest in equity and virtually all are in the capital market even at older ages (Tables 3 and 4, Case 3); the natural comparison is with the highly risk averse consumer in Case 4 who exits equities in favor of annuities at a much younger age. In Case 5, the asset allocation pattern seems quite reasonable: the worker starts with a high equity allocation and gradually moves into safer investments like bonds and annuities with age. We also note in Table 4 that this consumer has a high probability of participating in the financial market. Yet this seemingly realistic life cycle investment pattern stands in contrast to the unrealistically high and long worklife profile noted above, for this specification of preferences. Case 6 investment patterns are more consistent with priors, in that equity holdings are high for the young; during their 50's, the consumer is expected to switch into bonds and annuities and by age 65 to hold virtually no risky assets. But now the work patterns are more realistic than the prior case, since effort drops off with age as health deteriorates and they also retire early. In addition, the retirement peak at age 62 is also quite realistic (Table 2). ${ }^{17}$

\section{Conclusion}

This paper uses a realistically calibrated life cycle model to derive optimal work and

\footnotetext{
${ }^{17}$ Gustman and Steinmeier (2005) note two spikes in actual retirement patterns for US households: a main one at age 62 , and a smaller one at age 65 . Here we replicate two peaks, one at 62 and the secondary one at age 63 .
} 
retirement behavior, as well as consumption and investment strategy, taking into account stocks, bonds, and payout annuities. Prior portfolio allocation studies assume that the retirement age is set exogenously and predict that older people will hold unrealistically high levels of equity. Yet using prior studies' parameters, we show that few older persons will actually participate in the capital market at all, also incompatible with real-world evidence. Making labor supply endogenous raises older persons' equity share and substantially increases work effort of the young; it also affords significant lifetime welfare gains of $7 \%$ or more than $60 \%$ of first-year earnings. Introducing annuities then generates even more realistic models which permit earlier retirement and higher participation by the elderly in financial markets. Finally, our model with an age-dependent leisure preference parameter fits observed behavior remarkably well, incorporating a gradual decline in work hours and equity holdings with age, as well as a sensible dispersion in retirement ages which peak at age 62 , consistent with the evidence.

Evidently, combining work, investment, and lifetime payouts offers better and more attractive ways to manage life's many challenges. This is one reason that, though fixed payout annuities have been more prevalent in the marketplace to date, we anticipate investmentlinked payout annuities will become more popular as Baby Boomers age. 


\section{References:}

Benítez-Silva, H. and F. Heiland (2008). Early Claiming of Social Security Benefits and Labor Supply Behavior of Older Americans. Applied Economics, Taylor and Francis Journals 40, 29692985.

Bodie, Z., R. Merton, and W. Samuelson (1992). Labor Supply Flexibility and Portfolio Choice in a Life Cycle Model. Journal of Economic Dynamics and Control 16, 427-449.

Bodie, Z., J.B. Detemple, S. Otruba, and S. Walter (2004). Optimal Consumption-portfolio Choices and Retirement Planning. Journal of Economic Dynamics and Control 28, 1115-1148.

Brown, J., O.S. Mitchell, J. Poterba, and M. Warshawsky (1999). Taxing Retirement Income: Nonqualified Annuities and Distributions from Qualified Accounts. National Tax Journal 52, 563-586.

Buchinsky, M, Rust, J. and Benítez-Silva, H (2000). Dynamic Structural Models of Retirement and Disability. Yale University Department of Economics Working Paper.

Campbell, J., and L. Viceira. (2001). Who Should Buy Long-Term Bonds?. American Economic Review 91, 99-127.

Campbell, J., Y. Chan, and L. Viceira (2003). A Multivariate Model of Strategic Asset Allocation. Journal of Financial Economics 67, 41-80.

Chacko, G., and L. Viceira (2006). Dynamic Consumption and Portfolio Choice with Stochastic Volatility in Incomplete Markets. Review of Financial Studies 18, 1369-1402.

Chan, Y. L. and Viceira, L. M. (2000). Asset Allocation with Endogenous Labor Income: The Case of Incomplete Markets. Presented at the 2001 American Finance Association Meetings, New Orleans.

Cocco, J., F. Gomes, and P. Maenhout (2005). Consumption and Portfolio Choice over the Life Cycle. The Review of Financial Studies 18, 491-533.

Coile, C. P.A. Diamond; J. Gruber, and A. Jouston (2002). Delays in Claiming Social Security Benefits. Journal of Public Economics 84, 357-385.

Dybvig, P. H. and Liu, H. (2004). Lifetime Consumption and Investment: Retirement and Constrained Borrowing. Presented at the 2005 American Finance Association Meetings, Philadelphia.

Farhia, E. and Panageas, S. (2007). Saving and Investing for Early Retirement: A Theoretical Analysis. Journal of Financial Economics 83, 87-121.

Fehr, H., S. Jokisch, and L.J. Kotlikoff (2006). Will China Eat our Lunch or Take Us Out to Dinner? Simulating the Transition Paths of the US, EU, Japan and China. In: Takatoshi Ito and Andrew K. Rose (Eds.), Fiscal Policy and Management in East Asia. Chicago, University of Chicago Press, 133-198.

Feldstein, M. and E. Ranguelova (2001). Individual Risk in an Investment-Based Social Security System. American Economic Review 91, 1116-1125.

French, E. (2005). The Effects of Health, Wealth, and Wages on Labor Supply and Retirement Behaviour. Review of Economic Studies 72, 395-427.

Gomes, F., L. Kotlikoff, and L.M. Viceira (2008). Optimal Life-Cycle Investing with Flexible Labor Supply: A Welfare Analysis of Life-Cycle Funds. American Economic Review: Papers \& Proceedings 98, 297-303.

Gomes, F., and A. Michaelides (2005). Optimal Life-Cycle Asset Allocation: Understanding the Empirical Evidence. Journal of Finance 60, 869-904.

Gustman, A. L. and T. L. Steinmeier (2005). The Social Security Early Entitlement Age in a Structural Model of Retirement and Wealth. Journal of Public Economics 89, 441- 463.

Heaton, J. and D. Lucas (1997). Market Frictions, Savings and Portfolio Choice. Macroeconomic Dynamics $1,76-101$.

Horneff, W., R. Maurer, O.S. Mitchell, and I. Dus (2008). Following the Rules: Integrating Asset Allocation and Annuitization in Retirement Portfolios. Insurance: Mathematics and Economics 42, 396-408.

Horneff, W., R. Maurer, O.S. Mitchell, and M. Stamos (2008). Asset Allocation and Location Over the Life Cycle With Survival Contingent Payouts. Forthcoming in: Journal of Banking and Finance.

Horneff, W., R. Maurer, and M. Stamos (2008). Life-Cycle Asset Allocation with Annuity Markets. Journal of Economic Dynamics and Control 32, 3590-3612.

Horneff, W., R. Maurer, O.S Mitchell, and M. Stamos (2009). Variable Payout Annuities and 
Dynamic Portfolio Choice in Retirement. In press: Journal of Pension Economics and Finance. Hurd, M (1989). Mortality Risk and Bequest. Econometrica 57, 779-813.

Laitner, J. P. (2003). Labor Supply Responses to Social Security. Michigan Retirement Research Center Research Paper No. WP 2003-050.

Low, H. (2005). Self-insurance in a Life-cycle Model of Labor Supply and Savings. Review of Economic Dynamics 8, 945-975.

Milevsky, M. (2006). The Calculus of Retirement Income: Financial Models for Pension Annuities and Life Insurance. Cambridge: Cambridge University Press.

Milevsky, M., K. Moore, and V. Young (2006). Asset Allocation and Annuity-Purchase Strategies to Minimize The Probability of Financial Ruin. Mathematical Finance 16, 647-671.

Milevsky, M. and V. Young (2007). Annuitization and Asset Allocation. Journal of Economic Dynamics and Control 31, 3138-3177.

Mitchell, O.S., and G. Fields (1984). Retirement, Pensions, and Social Security. Cambridge, MA: MIT Press.

Mitchell, O.S. and J. Phillips (2006). Social Security Replacement Rates for Alternative Earnings Benchmarks. Benefits Quarterly 4, 37-47.

Mitchell, O.S., J. Poterba, M. Warshawsky, and J. Brown. 1999. New Evidence on the Money Worth of Individual Annuities. American Economic Review 89, 1299-1318.

Polkovnichenko, Valery (2007). Life-Cycle Portfolio Choice with Additive Habit Formation Preferences and Uninsurable Labor Income Risk. Review of Financial Studies 20, 83-124.

Viceira, L. (2001). Optimal Portfolio Choice for Long-Horizon Investors with Non-tradable Labor Income. Journal of Finance 56, 433-470.

Yao, R., and H. Zhang (2005). Optimal Consumption and Portfolio Choices with Risky Housing and Borrowing Constraints. The Review of Financial Studies 18, 197-239.

U.S. Social Security Administration (2009). Income of the Population 55 or Older, 2006. Office of Policy. Washington, D.C. Viewed 3-1-09.

www.ssa.gov/policy/docs/statcomps/income pop55/2006/sect02.html\#table2.a1 and http://www.ssa.gov/policy/docs/statcomps/income_pop55/2006/sect08.html\#table8.al1 


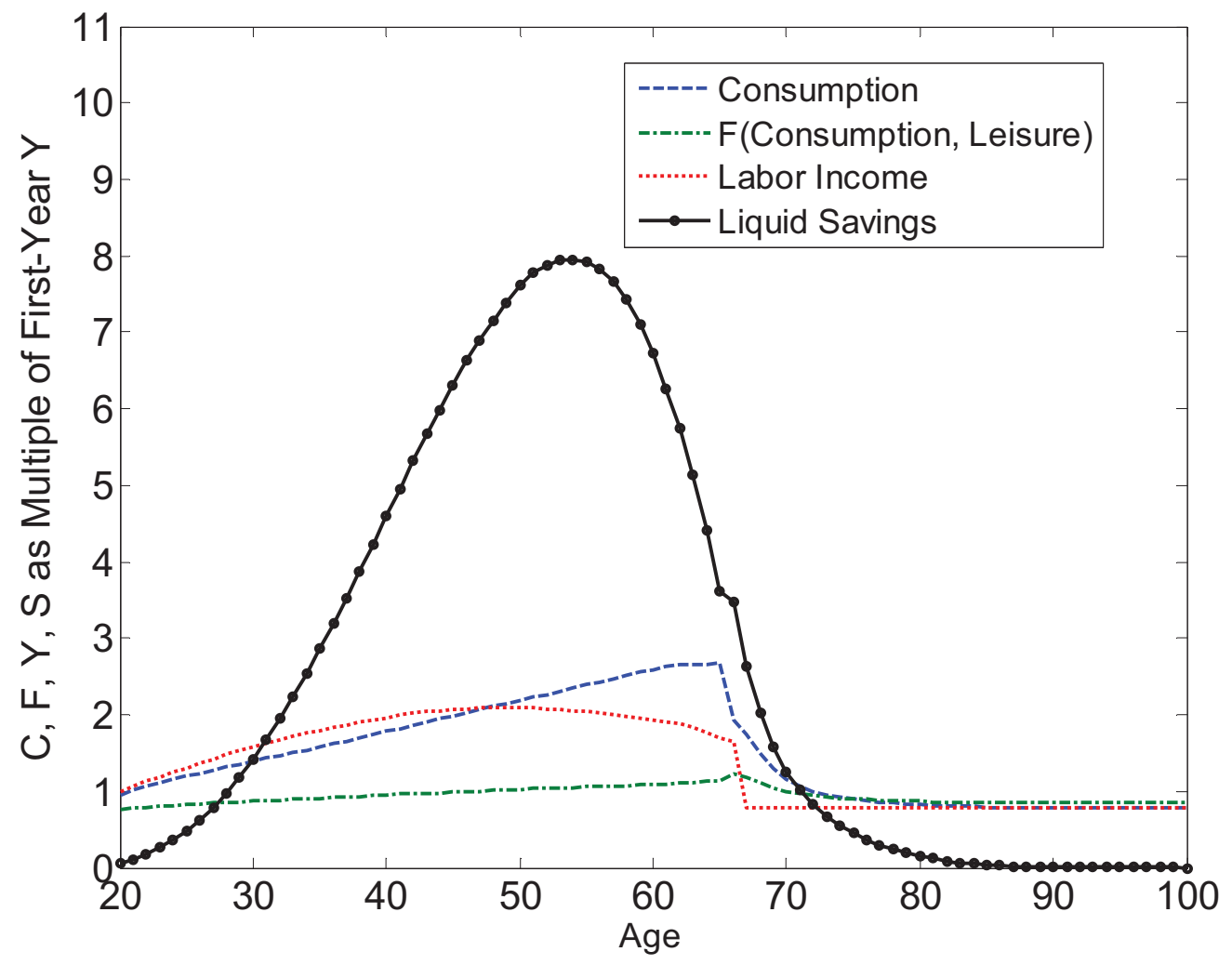

Figure 1: Optimal Expected Consumption, Labor Income, and Saving over the Life Cycle: Fixed Work Hours, Endogenous Retirement Age, and No Access to Annuity Markets. The graph displays expected consumption C, saving S, and labor income $\mathrm{Y}$ as a multiple of first-year labor earnings over the life cycle. Also shown is the value $F$ of the Cobb-Douglas function entering the utility function. Notes: The household has a moderate level of risk aversion $\rho$ of 5 and a discount rate $\beta$ of 0.97 ; the leisure preference parameter $\alpha$ is 0.59 . We use optimal feedback controls obtained from the stochastic optimization for a female with maximum lifespan of age 100; expectations are computed from 10,000 Monte Carlo simulations. 


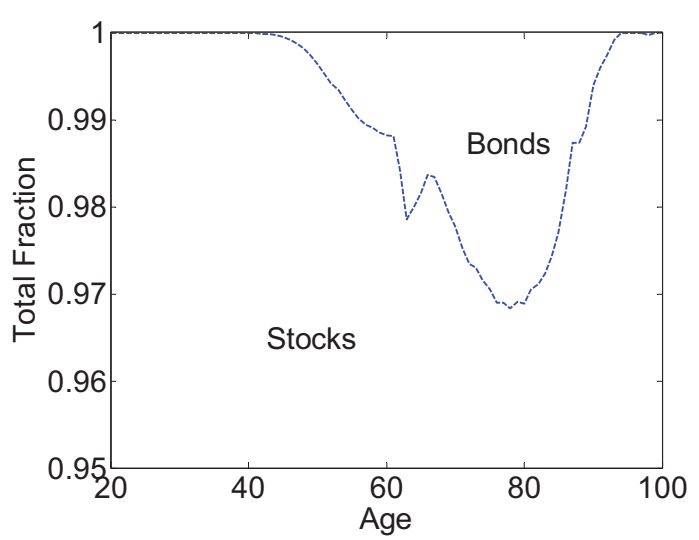

A. Asset Allocation Pattern by Age

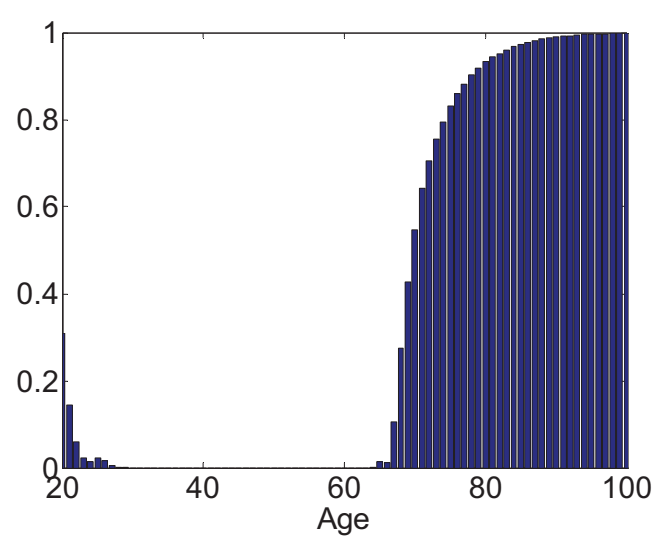

B. Capital Market Nonparticipation Rate by Age

Figure 2: Asset Allocation and Capital Market Nonparticipation Patterns by Age, Given Fixed Work Hours, Endogenous Retirement Age, and No Access to Annuity Markets. Panel A depicts the expected fraction of stocks and bonds over the life cycle, conditional on having minimally positive saving. Panel B displays the fraction of households not participating in the capital market by age. Notes: See Figure 1.

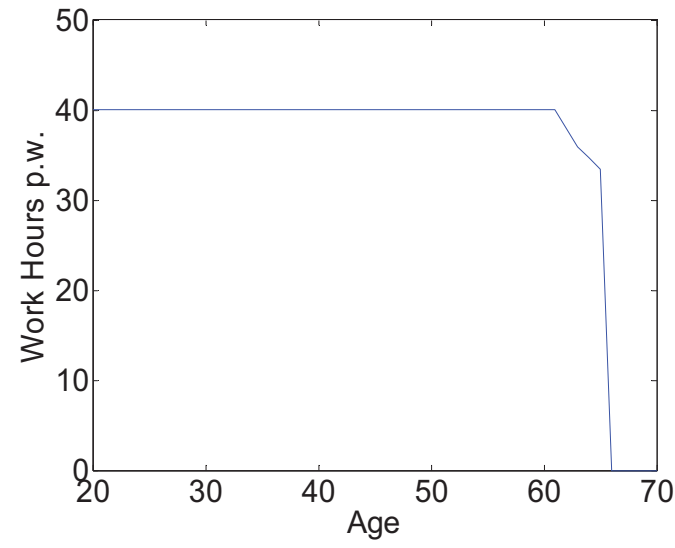

A. Average Weekly Hours by Age
Retirement Rate

\begin{tabular}{lc} 
Age & $(\%)$ \\
\hline \hline & \\
62 & 4.9 \\
63 & 5.3 \\
64 & 3.0 \\
65 & 3.2 \\
66 & 83.6 \\
67 & 0.0 \\
68 & 0.0 \\
69 & 0.0 \\
70 & 0.0 \\
\hline \hline
\end{tabular}

B. Retirement Rates by Age

Figure 3: Work Hours and Retirement Rates Over the Life Cycle Given Fixed Work Hours, Endogenous Retirement Age, and No Access to Annuity Markets. Panel A displays average hours worked per week from age 20 until 70 (the latest feasible retirement age). Panel B reports the percent of people retiring at each age from 62 to 70 . Notes: See Figure 1. 


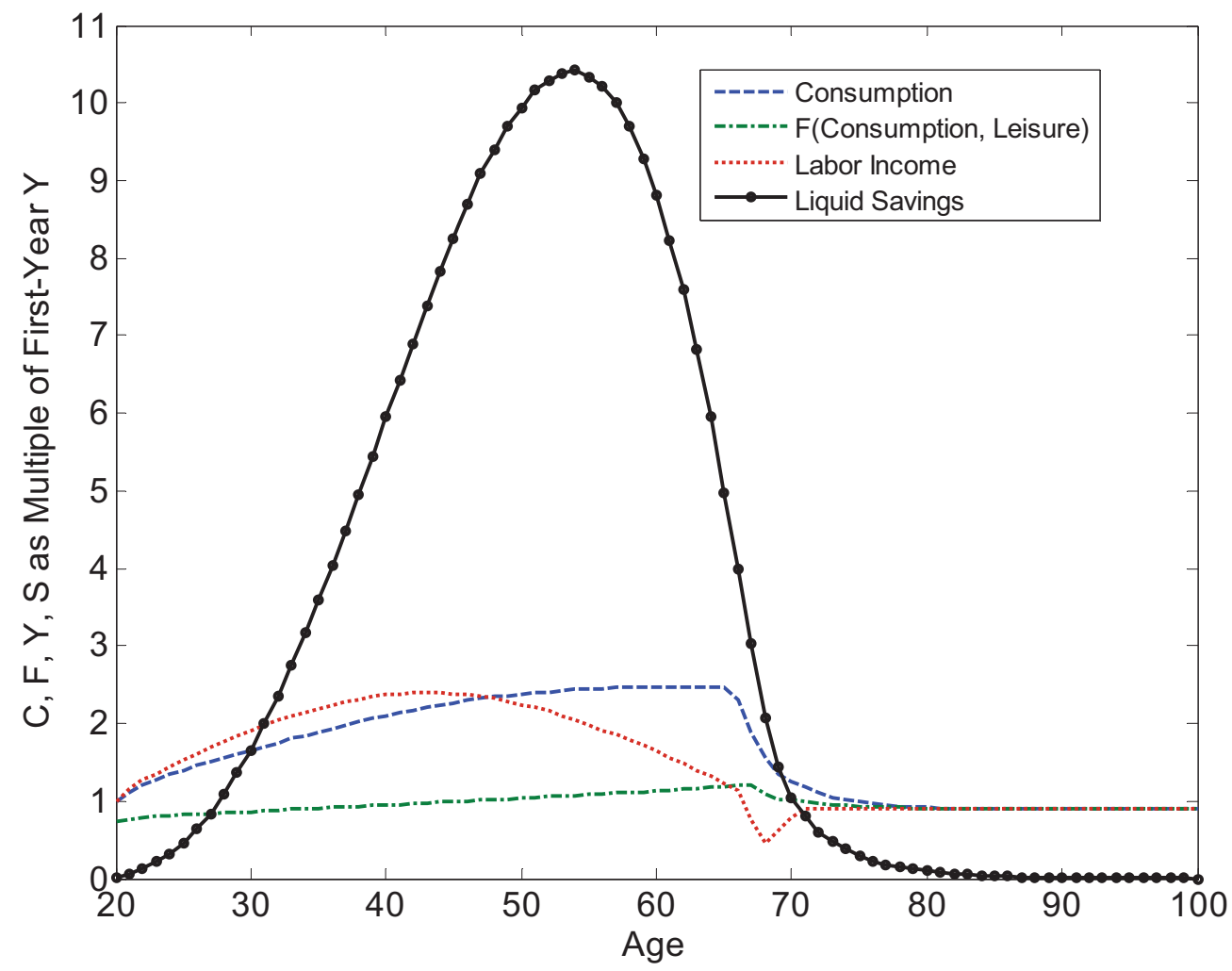

Figure 4: Optimal Expected Consumption, Labor Income, and Saving over the Life Cycle: Flexible Work Hours, Endogenous Retirement Age, and No Access to Annuity Markets. The graph displays expected consumption, saving, and labor income as a multiple of first-year labor earnings over the life cycle. Also shown is the value $F$ of the Cobb-Douglas function entering the utility function. Notes: See Figure 1. 


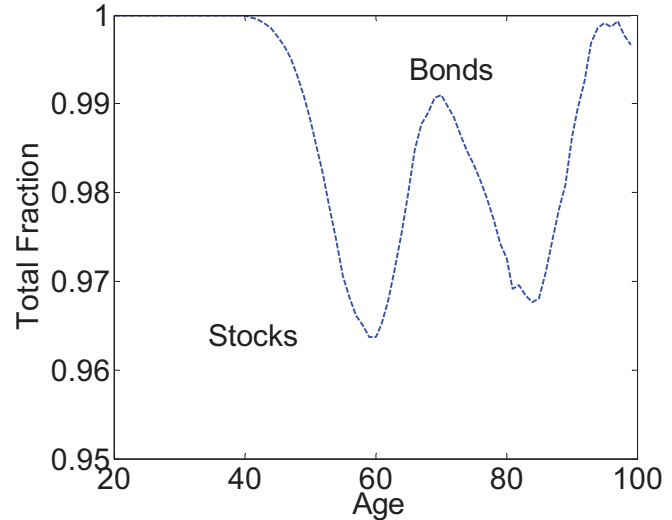

A. Asset Allocation Pattern by Age

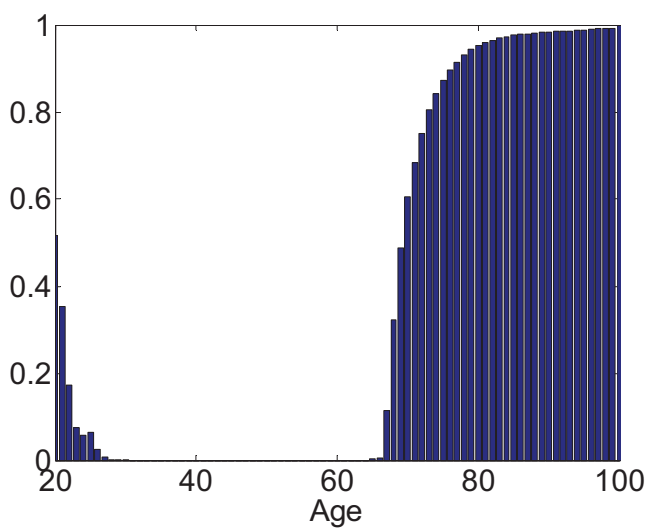

B. Capital Market Nonparticipation Rate by Age

Figure 5: Asset Allocation and Capital Market Nonparticipation Patterns by Age, Given Flexible Work Hours, Endogenous Retirement Age, and No Access to Annuity Markets. Panel A depicts the expected fraction of stocks and bonds over the life cycle, conditional on having minimally positive saving. Panel B displays the fraction of households not participating in the capital market by age. Notes: See Figure 1.

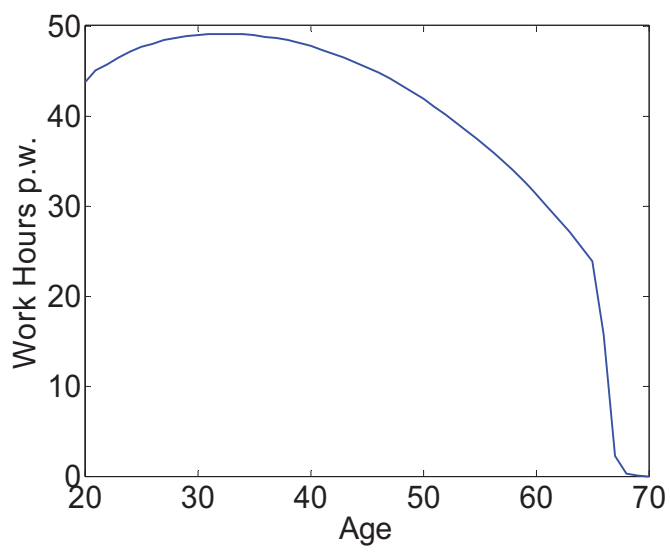

A. Average Weekly Hours by Age
Retirement Rate

\begin{tabular}{cc} 
Age & $(\%)$ \\
\hline \hline & \\
62 & 0 \\
63 & 0 \\
64 & 0 \\
65 & 0 \\
66 & 10.5 \\
67 & 32.5 \\
68 & 24.5 \\
69 & 17.1 \\
70 & 15.5 \\
\hline \hline
\end{tabular}

B. Retirement Rates by Age

Figure 6: Labor Supply over the Life Cycle: Flexible Work Hours, Endogenous

Retirement Age, and No Annuities. Panel A displays average hours worked per week from age 20 until 70 (the latest feasible retirement age). Panel B reports the percent of people retiring at each age from 62 to 70. Notes: See Figure 1. 


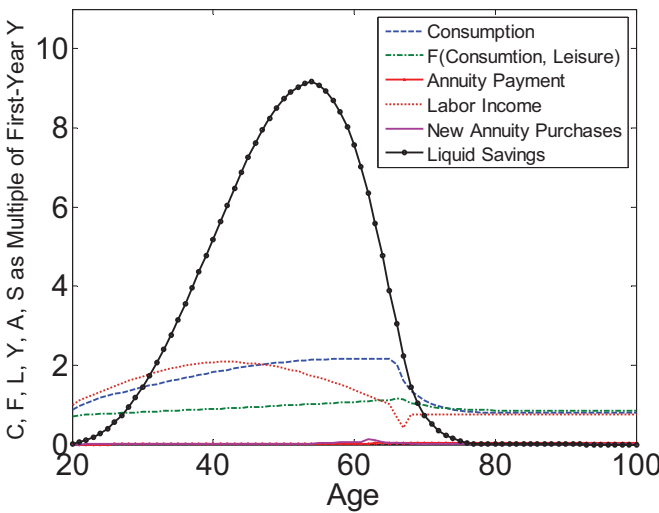

A. With Fixed Payout Annuities

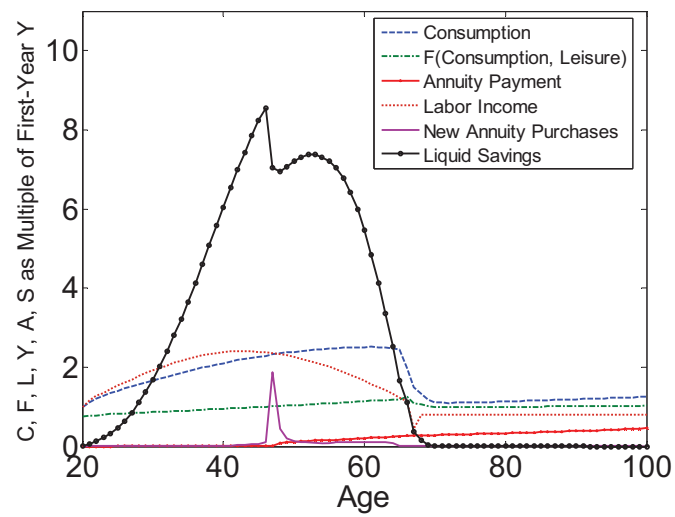

B. With Variable Payout Annuities

Figure 7: Optimal Expected Consumption, Labor Income, and Saving over the Life Cycle: Flexible Work Hours, Endogenous Retirement Age, with Fixed/Variable Payout Annuities. The graph displays expected consumption, saving, and labor income as a multiple of first-year labor earnings over the life cycle. Also shown is the value $F$ of the Cobb-Douglas function entering the utility function. Notes: Annuities are priced using the US annuitant 2000 mortality table $(A I R=2 \%$, loading factor 1.0238$)$. See also Figure 1 . 
(1) Fixed Annuities

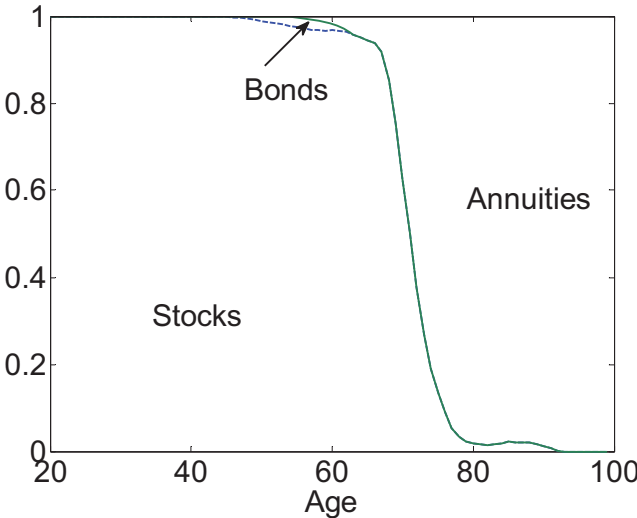

A. Asset Allocation Pattern by Age

(2) Variable Annuities

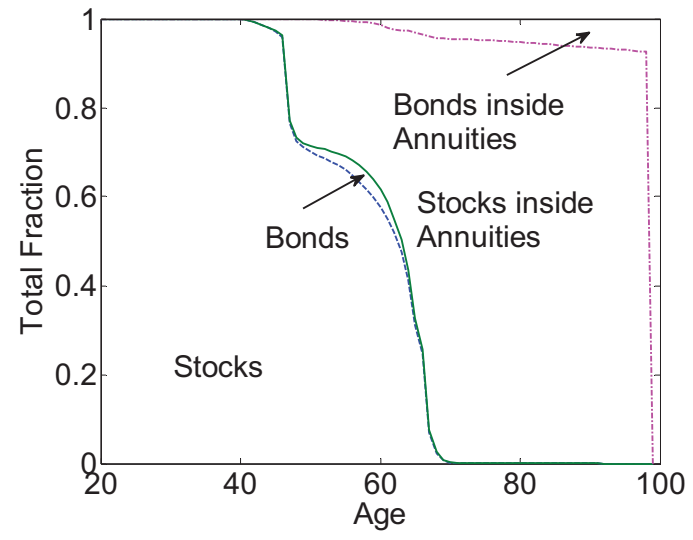

A. Asset Allocation Pattern by Age

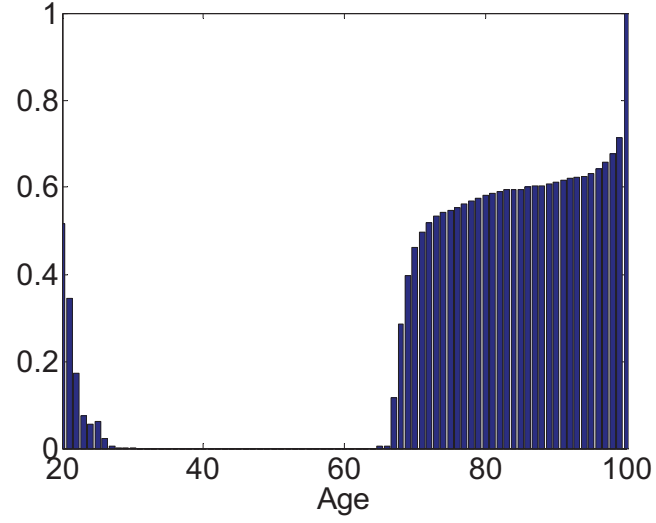

B. Capital Market Participation Rate by Age

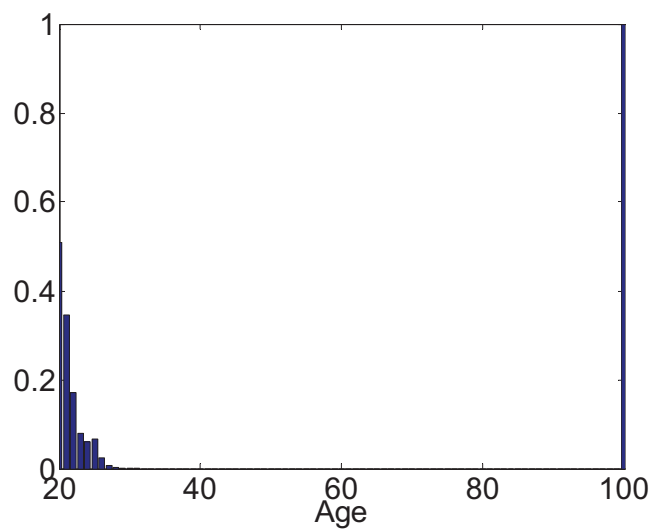

B. Capital Market Participation Rate by Age

Figure 8: Asset Allocation and Capital Market Nonparticipation Patterns by Age, Given Flexible Work Hours, Endogenous Retirement Age, with Fixed/Variable Annuities.

Conditional on having minimally positive liquid saving and expected present value of annuity payouts, Panel 1A depicts the expected trajectory for the fraction held in liquid stocks and bonds, and in the fixed annuity; Panel 2A plots the expected trajectory for the fraction held in stocks and bonds, inside and outside the variable annuity. Panels $1 \mathrm{~B}$ and 2B display the fraction of households not participating in the liquid capital or annuity markets by age. Notes: See Figure 7. 


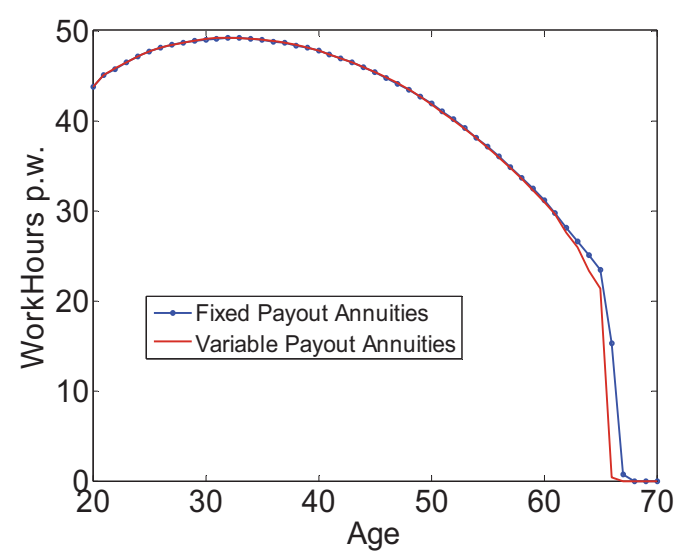

A. Average Weekly Hours by Age

\begin{tabular}{ccc} 
Age & \multicolumn{2}{c}{$\begin{array}{c}\text { Retirement Rate } \\
(\%)\end{array}$} \\
\hline \hline & Fixed & Variable \\
62 & 2.7 & 5.0 \\
63 & 2.0 & 3.4 \\
64 & 1.5 & 6.0 \\
65 & 0.5 & 3.8 \\
66 & 11.0 & 40.2 \\
67 & 39.2 & 41.6 \\
68 & 43.1 & 0 \\
69 & 0 & 0 \\
70 & 0 & 0 \\
\hline \hline
\end{tabular}

B. Retirement Rates by Age

Figure 9: Labor Supply over the Life Cycle: Flexible Work Hours, Endogenous

Retirement Age, with Fixed/Variable Payout Annuities. Panel A displays average hours worked per week from age 20 until 70 (the latest feasible retirement age). Panel B reports the percent of people retiring at each age from 62 to 70. Notes: See Figure 7. 


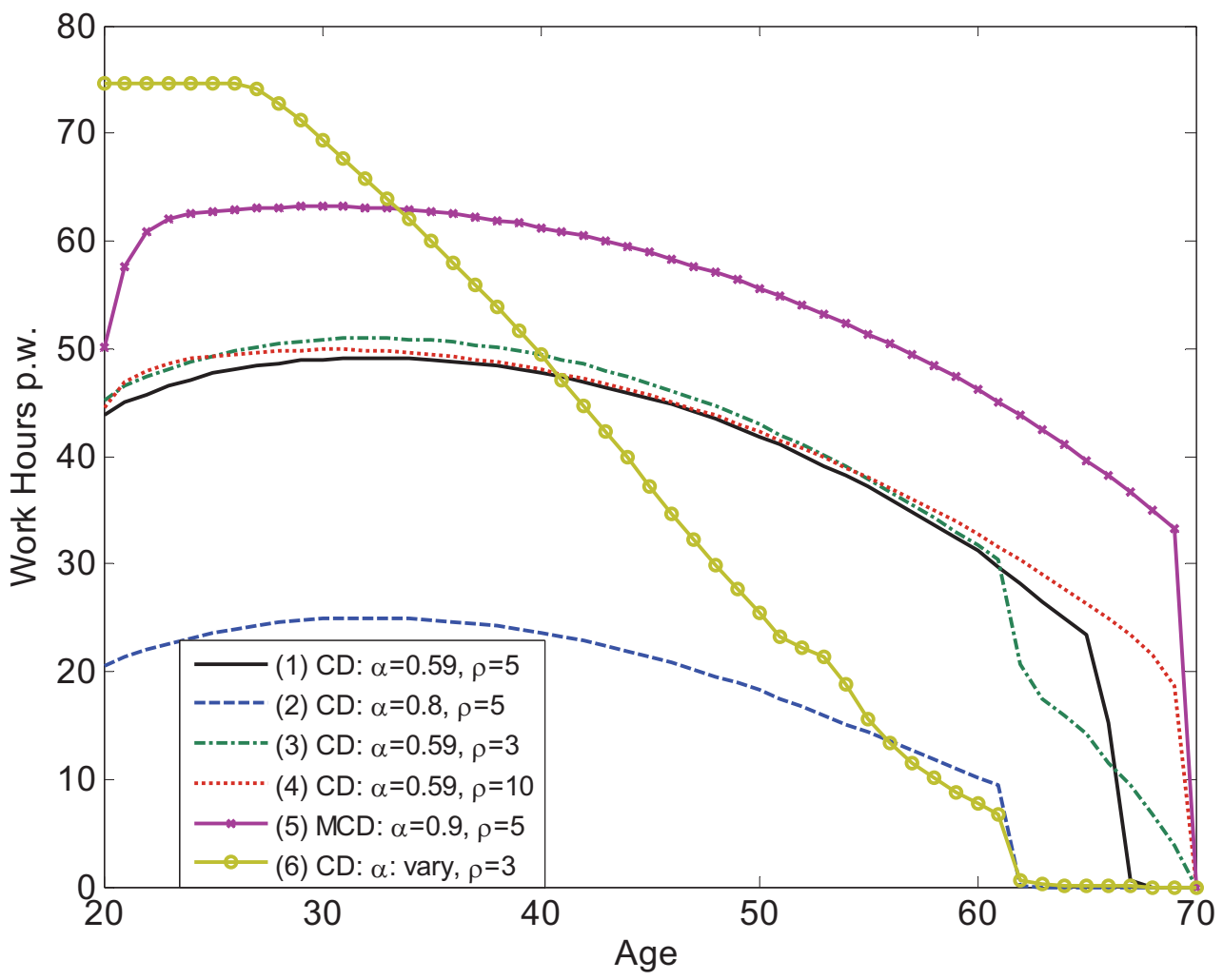

Figure 10: Labor Supply Patterns Over the Life Cycle for Alternative Utility Parameters Given Flexible Work Hours and Endogenous Retirement Age, with Fixed Payout

Annuities. The Figure displays the average hours worked per week for six alternative utility function settings. Case (1) is the reference case with a Cobb-Douglas (CD) utility function where $\alpha$ equals 0.59 and $\rho$ is 5 . Case (2) has $\alpha$ set at 0.8 , i.e. the investor prefers to have much more leisure time. For Case (3), the investor becomes less risk-averse so $\rho$ is 3 , and more risk averse in Case (4) where $\rho$ is 10. In Case (5) we use a modified Cobb-Douglas (MCD) with $\alpha$ set at 0.9 to capture a stronger leisure preference. For Case (6) we use an age-dependent $\alpha$ to allow for a gradual decline in the utility of leisure associated with poorer health at older ages; as in Buchinski et al. (2000). $\alpha(\mathrm{t})$ is given by $\alpha=1-0.6 /(1+\mathrm{t} / 50)$, where $t$ is the period. Notes: See Figure 7. 


\begin{tabular}{lllccc}
\hline $\begin{array}{l}\text { Work } \\
\text { Hours }\end{array}$ & $\begin{array}{l}\text { Retirement } \\
\text { Age }\end{array}$ & $\begin{array}{l}\text { Annuity } \\
\text { Market }\end{array}$ & & $\begin{array}{c}\text { Relative } \\
\text { Utility Gains } \\
(\%)\end{array}$ & $\begin{array}{c}\text { Welfare Gain: \% of } \\
\text { 1st yr Labor } \\
\text { Income } \\
\text { (a) }\end{array}$ \\
\hline (0) Fixed & Fixed & No & & Reference & Reference \\
(1) Fixed & Flexible & No & & $4.4 \%$ & $49.5 \%$ \\
(2) Flexible & Flexible & No & & $6.6 \%$ & $61.3 \%$ \\
(3) Flexible & Flexible & Fixed & & $6.8 \%$ & $61.4 \%$ \\
(4) Flexible & Flexible & Variable & & $7.0 \%$ & $62.4 \%$ \\
\hline
\end{tabular}

Table 1: Calculation of Welfare Gains. This table reports utility gains as consumptionequivalent variations computed with reference to Row (0) which refers to the lifetime utility level of a consumer with fixed hours and retirement age, and lacking access to annuity markets. Rows ( 1 and 2) allow the worker to select a flexible retirement age but differ with regard to work hour flexibility. Rows ( 3 and 4 ) have both flexible hours and retirement age, but in the former case fixed annuities are available, and in the latter case, variable annuities are available. The last column reports the fraction of the worker's first year labor income he would give up, in exchange for the additional lifetime flexibility that would make him indifferent relative to the reference case. Notes: See Figure 7. 


\begin{tabular}{|c|c|c|c|c|c|c|c|c|c|c|c|c|c|c|c|c|c|c|}
\hline \multirow[b]{3}{*}{ Age } & \multicolumn{18}{|c|}{ Retirement Ratio (\%) } \\
\hline & \multicolumn{3}{|c|}{ (1) } & \multicolumn{3}{|c|}{ (2) } & \multicolumn{3}{|c|}{ (3) } & \multicolumn{3}{|c|}{ (4) } & \multicolumn{3}{|c|}{ (5) } & \multicolumn{3}{|c|}{ (6) } \\
\hline & $\begin{array}{c}\alpha \\
0.59\end{array}$ & $\begin{array}{l}\rho \\
5\end{array}$ & $C D$ & $\begin{array}{c}\alpha \\
0.8\end{array}$ & $\begin{array}{l}\rho \\
5\end{array}$ & $C D$ & $\begin{array}{c}\alpha \\
0.59\end{array}$ & $\begin{array}{l}\rho \\
3\end{array}$ & $C D$ & $\begin{array}{c}\alpha \\
0.59\end{array}$ & $\begin{array}{c}\rho \\
10\end{array}$ & $C D$ & $\begin{array}{c}\alpha \\
0.9\end{array}$ & $\begin{array}{l}\rho \\
5\end{array}$ & MCD & $\begin{array}{c}\alpha \\
\text { vary }\end{array}$ & $\begin{array}{l}\rho \\
3\end{array}$ & $C D$ \\
\hline 62 & & 2.7 & & & 50.2 & & & 22.4 & & & 0.3 & & & 0.2 & & & 49.6 & \\
\hline 63 & & 2.0 & & & 49.8 & & & 15.6 & & & 0.3 & & & 0.2 & & & 24.6 & \\
\hline 64 & & 1.5 & & & 0 & & & 8.6 & & & 0.2 & & & 0.2 & & & 12.8 & \\
\hline 65 & & 0.5 & & & 0 & & & 6.1 & & & 0.1 & & & 0.3 & & & 6.5 & \\
\hline 66 & & 11.0 & & & 0 & & & 6.8 & & & 0.1 & & & 0.3 & & & 3.3 & \\
\hline 67 & & 39.2 & & & 0 & & & 6.2 & & & 0.3 & & & 0.3 & & & 1.7 & \\
\hline 68 & & 43.1 & & & 0 & & & 7.3 & & & 2.3 & & & 1.1 & & & 1.5 & \\
\hline 69 & & 0 & & & 0 & & & 8.3 & & & 7.0 & & & 1.2 & & & 0 & \\
\hline 70 & & 0 & & & 0 & & & 18.8 & & & 89.4 & & & 96.3 & & & 0 & \\
\hline
\end{tabular}

Table 2: Retirement Rates for Alternative Utility Parameters Given Flexible Work Hours, Endogenous Retirement Age, and Fixed Payout Annuities. The table shows the stocks/bonds/annuities fraction at age 35, 50, 65 and 80 for the six alternative utility function settings described in Figure 10. Notes: See Figure 10. 


\begin{tabular}{|c|c|c|c|c|c|c|c|c|c|c|c|c|c|c|c|c|c|c|c|}
\hline \multirow[b]{3}{*}{ Age } & \multirow[b]{3}{*}{ Fraction } & \multicolumn{18}{|c|}{ Asset Allocation (\%) } \\
\hline & & \multicolumn{3}{|c|}{ (1) } & \multicolumn{3}{|c|}{ (2) } & \multicolumn{3}{|c|}{ (3) } & \multicolumn{3}{|c|}{ (4) } & \multicolumn{3}{|c|}{ (5) } & \multicolumn{3}{|c|}{ (6) } \\
\hline & & $\begin{array}{c}\alpha \\
0.59\end{array}$ & $\begin{array}{l}\rho \\
5\end{array}$ & $C D$ & $\begin{array}{c}\alpha \\
0.8\end{array}$ & $\begin{array}{l}\rho \\
5\end{array}$ & $C D$ & $\begin{array}{c}\alpha \\
0.59\end{array}$ & $\begin{array}{l}\rho \\
3\end{array}$ & $C D$ & $\begin{array}{c}\alpha \\
0.59\end{array}$ & $\begin{array}{c}\rho \\
10\end{array}$ & $C D$ & $\begin{array}{c}\alpha \\
0.9\end{array}$ & $\begin{array}{l}\rho \\
5\end{array}$ & $\mathrm{MCD}$ & $\begin{array}{c}\alpha \\
\text { vary }\end{array}$ & $\begin{array}{l}\rho \\
3\end{array}$ & $C D$ \\
\hline \multirow{3}{*}{35} & Stocks & \multicolumn{3}{|c|}{100.0} & \multicolumn{3}{|c|}{100.0} & \multicolumn{3}{|c|}{100.0} & \multicolumn{3}{|c|}{98.9} & \multicolumn{3}{|c|}{97.5} & \multicolumn{3}{|c|}{98.7} \\
\hline & Bonds & \multicolumn{3}{|c|}{0} & \multicolumn{3}{|c|}{0} & \multicolumn{3}{|c|}{0} & \multicolumn{3}{|c|}{1.1} & \multicolumn{3}{|c|}{2.5} & \multicolumn{3}{|c|}{0} \\
\hline & Annuities & \multicolumn{3}{|c|}{0} & \multicolumn{3}{|c|}{0} & \multicolumn{3}{|c|}{0} & \multicolumn{3}{|c|}{0} & \multicolumn{3}{|c|}{0} & \multicolumn{3}{|c|}{1.3} \\
\hline \multirow{3}{*}{50} & Stocks & \multicolumn{3}{|c|}{98.9} & \multicolumn{3}{|c|}{99.7} & \multicolumn{3}{|c|}{99.5} & & 66.1 & & & 58.7 & & & 79.0 & \\
\hline & Bonds & & 1.1 & & & 0.3 & & & 0.3 & & & 8.5 & & & 4.8 & & & 10.2 & \\
\hline & Annuities & & 0 & & & 0 & & & 0.2 & & & 25.4 & & & 36.5 & & & 10.8 & \\
\hline & Stocks & & 94.5 & & & 97.3 & & & 76.5 & & & 43.8 & & & 32.1 & & & 59.1 & \\
\hline 65 & Bonds & & 0 & & & 0 & & & 0 & & & 1 & & & 0 & & & 0 & \\
\hline & Annuities & & 5.5 & & & 2.7 & & & 23.5 & & & 55.6 & & & 67.9 & & & 40.9 & \\
\hline & Stocks & & 1.9 & & & 38.4 & & & 8.9 & & & 1.8 & & & 1.1 & & & 3.7 & \\
\hline 80 & Bonds & & 0 & & & 0 & & & 0 & & & 0 & & & 0 & & & 0 & \\
\hline & Annuities & & 98.1 & & & 61.6 & & & 91.1 & & & 98.2 & & & 98.9 & & & 96.3 & \\
\hline
\end{tabular}

Table 3: Expected Asset Allocation Patterns for Alternative Utility Parameters Given Flexible Work Hours, Endogenous Retirement Age, and Fixed Payout Annuities. The table shows the stocks/bonds/annuities fraction at age 35, 50,65 and 80 for the six alternative utility function settings described in Figure 10. Notes: See Figure 10. 


\begin{tabular}{|c|c|c|c|c|c|c|c|c|c|c|c|c|c|c|c|c|c|c|}
\hline & \multicolumn{18}{|c|}{ Non-Participation (\%) } \\
\hline & \multicolumn{3}{|c|}{ (1) } & \multicolumn{3}{|c|}{ (2) } & \multicolumn{3}{|c|}{ (3) } & \multicolumn{3}{|c|}{ (4) } & \multicolumn{3}{|c|}{ (5) } & \multicolumn{3}{|c|}{ (6) } \\
\hline & $\begin{array}{c}\alpha \\
0.59\end{array}$ & $\begin{array}{l}\rho \\
5\end{array}$ & $C D$ & $\begin{array}{c}\alpha \\
0.8\end{array}$ & $\begin{array}{l}\rho \\
5\end{array}$ & $C D$ & $\begin{array}{c}\alpha \\
0.59\end{array}$ & $\begin{array}{l}\rho \\
3\end{array}$ & $C D$ & $\begin{array}{c}\alpha \\
0.59\end{array}$ & $\begin{array}{c}\rho \\
10\end{array}$ & $C D$ & $\begin{array}{c}\alpha \\
0.9\end{array}$ & $\begin{array}{l}\rho \\
5\end{array}$ & $\mathrm{MCD}$ & $\begin{array}{c}\alpha \\
\text { vary }\end{array}$ & $\begin{array}{l}\rho \\
3\end{array}$ & $\mathrm{CD}$ \\
\hline & \multicolumn{18}{|c|}{ Young: Age 20-29 } \\
\hline Mean & \multicolumn{3}{|c|}{$12.6 \%$} & \multicolumn{3}{|c|}{$0.1 \%$} & \multicolumn{3}{|c|}{$9.7 \%$} & \multicolumn{3}{|c|}{$7.5 \%$} & \multicolumn{3}{|c|}{$11.6 \%$} & \multicolumn{3}{|c|}{$0.5 \%$} \\
\hline Standard Deviation & \multicolumn{3}{|c|}{$17.3 \%$} & \multicolumn{3}{|c|}{$0.1 \%$} & \multicolumn{3}{|c|}{$17.4 \%$} & \multicolumn{3}{|c|}{$13.1 \%$} & \multicolumn{3}{|c|}{$21.5 \%$} & \multicolumn{3}{|c|}{$0.5 \%$} \\
\hline & \multicolumn{18}{|c|}{ Old: Age 65-99 } \\
\hline Mean & \multicolumn{3}{|c|}{$53.0 \%$} & \multicolumn{3}{|c|}{$18.8 \%$} & \multicolumn{3}{|c|}{$1.0 \%$} & \multicolumn{3}{|c|}{$0 \%$} & \multicolumn{3}{|c|}{$0 \%$} & \multicolumn{3}{|c|}{$0 \%$} \\
\hline Standard Deviation & \multicolumn{3}{|c|}{$17.1 \%$} & \multicolumn{3}{|c|}{$15.5 \%$} & \multicolumn{3}{|c|}{$0.8 \%$} & \multicolumn{3}{|c|}{$0 \%$} & \multicolumn{3}{|c|}{$0 \%$} & \multicolumn{3}{|c|}{$0 \%$} \\
\hline
\end{tabular}

Table 4: Capital Market Nonparticipation Rates for Alternative Utility Parameters by Age, Given Flexible Labor Hours, Endogenous Retirement Age, and Fixed Payout Annuities. The top panel depicts the mean and standard deviation of nonparticipation for young persons age 20 to 29 in the six alternative utility function settings described in Figure 10. The second panel shows results for nonparticipation rates for persons age 65-99. Market participation rates are $100 \%$ for middle-aged individuals. Notes: See Figure 10. 


\section{Technical Appendix: Calculating the Utility-Constant Equivalent Consumption Stream} (CE)

For each case, the expected lifetime utility from consumption and leisure at $\mathrm{t}=1$ is given by:

$V=E_{1}\left(\sum_{t=1}^{T=81} \beta^{t-1}\left(\prod_{i=1}^{t} p_{i}^{s}\right) \frac{\left(C_{t}^{1-\alpha} L_{t}^{\alpha}\right)^{1-\rho}}{1-\rho}\right)$,

where $C_{t}$ and $L_{t}$ are optimized in each model variant. In each case, we calculate the constant consumption stream $\mathrm{CE}$ for an investor with fixed work hours who retires at the normal retirement age and who does not have access to annuities. This constant consumption stream CE makes her as well-off in expected utility terms at age 20 as the leisure and consumption stream that can be financed by the life cycle strategy. CE is defined as follows:

$$
\begin{aligned}
& V_{1}=\sum_{t=1}^{K-1=45} \beta^{t-1}\left(\prod_{i=1}^{t} p_{i}^{s}\right) \frac{\left(C E^{1-\alpha} L_{w l}^{\alpha}\right)^{1-\rho}}{1-\rho}+\sum_{t=K=46}^{T=81} \beta^{t-1}\left(\prod_{i=1}^{t} p_{i}^{s}\right) \frac{\left(C E^{1-\alpha} 1^{\alpha}\right)^{1-\rho}}{1-\rho} \\
& \Rightarrow C E=\left[\frac{V_{1}(1-\rho)}{\sum_{t=1}^{K-1=45} \beta^{t-1}\left(\prod_{i=1}^{t} p_{i}^{s}\right) L_{w l}^{\alpha(1-\rho)}+\sum_{t=k=46}^{T=81} \beta^{t-1}\left(\prod_{i=1}^{t} p_{i}^{s}\right)}\right]
\end{aligned}
$$

